\title{
Production of Surface Active Glycolipid by Serratia marcescens NSK-1 Isolated from Petroleum Contaminated Soil
}

\author{
C.U. Anyanwu, S.K.C. Obi and B.N. Okolo \\ Department of Microbiology, University of Nigeria, Nsukka, Nigeria \\ *E-mail: chudizoma@yahoo.com
}

Received: 26.01.2010, Accepted: 07.10.2010

\begin{abstract}
Biosurfactant-producing Serratia marcescens NSK-1 strain was isolated from soil contaminated with petroleum products. The organism, when grown in mineral salts medium with sucrose as sole carbon source, produced a surface-active anthrone-positive glycolipid. The biosurfactant was partially purified by liquid-liquid partition chromatography in chloroform-methanol mixture (1:1) and silica gel chromatography. It reduced the surface tension of distilled water from 72 dynes $/ \mathrm{cm}$ to 40 dynes $/ \mathrm{cm}$ and exhibited good emulsification activity with some vegetable oils and hydrocarbons. The biosurfactant exhibited stable surface activity over a wide range of temperature (30$\left.100^{\circ} \mathrm{C}\right), \mathrm{pH}(2-12)$ and salt concentration. There was no significant toxic effect shown by the biosurfactant towards mice when tested using the World Health Organization guidelines.
\end{abstract}

Key words: Biosurfactant, bioemulsifier, emulsification, surface tension, Serratia marcescens

\section{Introduction}

Biosurfactants the surface-active compounds produced by microorganisms comprise a wide range of chemical structures such as glycolipids, lipopeptides, polysaccharide-protein complexes, phospholipids, fatty acids and neutral lipids (Mulligan, 2005; Neto et al., 2008). Glycolipids viz. rhamnolipids, trehalolipids, and sophorolipids are the most known biosurfactants in which carbohydrates such as rhamnose, sophorose, trehalose or fructose are attached to a long chain fatty acid (Calvo et al., 2004). The lipopeptides are the amino acid containing biosurfactants like surfactin produced by Bacillus subtilis (Lin, 1996). Other biopolymers of this group include the decapeptide antibiotics (gramicidins) and lipopeptide antibiotics (polymyxins) produced by different species of Bacillus. Several bacteria and yeasts have been reported to produce large quantities of fatty acid and phospholipid surfactants when grown on $\mathrm{n}$-alkanes (Cirigliano and Carman, 1984; Desai and Banat, 1997).

Surfactants and emulsifiers are widely used in the pharmaceutical, cosmetic, petroleum, food industries and agriculture. However, most of these compounds synthesized chemically are toxic to environments, not easily biodegradable, and their manufacturing processes and byproducts can be environmentally hazardous (Maier and Soberon, 2000). But, biosurfactants commonly have the 
advantages of biodegradability, low toxicity and biocompatibility over chemically synthesized surfactants (Mohan et al., 2006). In addition, they can potentially be synthesized from renewable and cheaper substrates (Desai and Banat, 1997; Rosenberg and Ron, 1999), and are commonly effective at extremes of $\mathrm{pH}$, temperature and salinity (Georgiou et al., 1992). Much interest has currently centered on surface active microbial products i.e., biosurfactants as an alternative source of surfactants.

The range of industrial applications of biosurfactants includes enhanced oil recovery, crude oil drilling, bioremediation of pollutants, health care and food processing (Cameotra and Makkar, 2004; Hickey et al., 2007; Dastgheib et al., 2008). Biosurfactants have found applications as therapeutic agents and in combating many diseases. In agriculture, biosurfactants are used to dilute and disperse fertilizers and pesticides and to enhance penetration of active compounds into plants. Surface active agents are needed for hydrophilization of heavy soils to obtain good wettability and also achieve equal distribution of fertilizers and pesticides in the soils (Calvo et al., 2004). Accordingly, the screening of new microbial surfactants has intensified. They will become important industrial chemicals as yields of biosurfactants in production processes are improved and the potential for the substitution of existing synthetic surfactants is further evaluated.

Many types of surface active agents are synthesized by a wide variety of microorganisms. Mostly, they exhibit the typical amphiphilic character of lipids but they are generally extracellular (Kim et al., 2006). The most often isolated and most thoroughly studied biosurfactants are the structurally homogeneous glycolipids e.g., sophorose lipids, rhamnolipids and trehalose lipids. The glycolipids are the microbial surfactants or emulsifying agents that contain carbohydrate in combination with long chain aliphatic acids. Glycolipids have been produced by a variety of microorganisms including Pseudomonas aeruginosa, Arthrobacter sp., Corynebacterium sp., Rhodococcus erythropolis, and Serratia spp (Mulligan, 2005).

In the present work, we have reported the production of glycolipid biosurfactant by an indigenous tropical strain of Serratia marcescens isolated from petroleumcontaminated soil. Some of the properties and initial characterization of the product obtained are also presented.

\section{Materials and methods \\ Microorganism and culture conditions}

A strain of Serratia marcescens NSK-1 was used throughout this work. It was isolated in our laboratory from petroleumcontaminated soil as described by Anyanwu et al. (2008), and maintained on nutrient agar slants at a refrigeration temperature of $4^{\circ} \mathrm{C}$. Each seed culture was prepared by inoculating a loop of the stock culture into $20 \mathrm{ml}$ of nutrient broth, within a 200-ml conical flask. That was incubated at $30^{\circ} \mathrm{C}$ and $180 \mathrm{rev} / \mathrm{min}$ for $8-12 \mathrm{~h}$. An aliquot of $2.5 \mathrm{ml}$ of inoculum was transferred to 250 $\mathrm{ml}$ Erlenmeyer flask containing $50 \mathrm{ml}$ of a liquid medium with the following composition (g/l): $\mathrm{K}_{2} \mathrm{HPO}_{4}, 4.5 ; \mathrm{KH}_{2} \mathrm{PO}_{4}$, 2.0; $\left(\mathrm{NH}_{4}\right)_{2} \mathrm{SO}_{4}, 3.0 ; \mathrm{MgSO}_{4} .7 \mathrm{H}_{2} 0,0.01$; $\mathrm{FeSO}_{4} .7 \mathrm{H}_{2} 0,0.01$ and Sucrose, 20.0. The $\mathrm{pH}$ of the medium was adjusted to 7.0. All experiments were carried out in triplicates. 
The incubation was carried out on a rotary shaker (Gallenkamp) at $180 \mathrm{rev} / \mathrm{min}$ and $30^{\circ} \mathrm{C}$ for three days.

Culture samples were taken at regular intervals during the incubation period and analyzed for viable cell numbers, $\mathrm{pH}$, surfactant concentration and surface tension. Control experiments were set up in parallel with inoculated flasks at the same conditions. Viable cell numbers were determined by the spread plate technique on nutrient agar (Lab M) using serially diluted culture samples and incubated for $24-48 \mathrm{hr}$ at $30^{\circ} \mathrm{C}$. All chemicals and reagents used were of analytical grade and obtained from Sigma-Aldrich Chemical Co., Inc.

\section{Biosurfactant isolation}

Culture broth of Serratia marcescens NSK$1 \mathrm{was}$ centrifuged at $10,000 \mathrm{xg}$ for $15 \mathrm{~min}$ to obtain cell-free supernatant. The supernatant was extracted three times with equal volumes of chloroform-methanol (1:1, $\mathrm{v} / \mathrm{v})$ mixture. The pooled extracts were evaporated to dryness at $45-50^{\circ} \mathrm{C}$ and the residue obtained was washed with distilled water and re-extracted after which the solvent was evaporated.

\section{Adsorption chromatography on silica gel}

The residue was dissolved in chloroformmethanol mixture and applied to a silica gel 60 (Aldrich, Milwaukee, Wis.) chromatography column $(2.0 \mathrm{~cm}$ by 30.0 $\mathrm{cm})$ and eluted with chloroform-methanol (5:1) mixture. The column was first washed with chloroform to elute out non-polar compounds and pigments. The effluent obtained was concentrated by evaporating the solvent.

\section{Thin layer chromatography (TLC)}

It was carried out by spotting the concentrated residue on precoated TLC plates (Merck, Germany) and developed in the following solvent systems, chloroformmethanol-acetic acid (85:10:5) and nhexane-ethyl ether-acetic acid (80:20:1) (Suzuki et al., 1974). Detection of materials on the plates was done after air-drying by spraying the developed plates with anthrone-sulphuric acid and $\alpha$-naphtholsulphuric acid solutions, respectively, and heated at $100^{\circ} \mathrm{C}$ for $5 \mathrm{~min}$.

\section{Biochemical analysis}

Carbohydrate content of the biosurfactant was estimated by the method of Dubois (1956) using glucose $\left(0-80 \mu \mathrm{g} \mathrm{ml}^{-1}\right)$ as standard. Protein content was determined by the AOAC method (1980) of Kjeldahl digestion in sulphuric acid while lipid content was determined by extracting a portion of the biosurfactant $(0.5 \mathrm{~g})$ with 25 $\mathrm{ml}$ of diethyl ether in a water bath at $50^{\circ} \mathrm{C}$ for $30 \mathrm{~min}$ (Pruthi and Cameotra, 1997). The ether extract was dried by filtering through anhydrous $\mathrm{Na}_{2} \mathrm{SO}_{4}$ and the filtrate clarified and weighed.

\section{Identification of sugar moiety}

The sugar moiety of the glycolipid biosurfactant was determined by the method of Suzuki et al. (1974). The glycolipid (100 $\mathrm{mg}$ ) was hydrolyzed with $5 \mathrm{~mL}$ of $0.5 \mathrm{M}$ sodium hydroxide (90\% ethanol solution) at $55^{\circ} \mathrm{C}$ for $60 \mathrm{~min}$. At the end of the hydrolysis, the hydrolysate was neutralized to $\mathrm{pH} 7.0$ with hydrochloric acid and extracted three times with equal volumes of diethyl ether. The aqueous and ether extracts were separately pooled together and the aqueous phase evaporated. 
The water-soluble fraction of the hydrolysate was subjected to thin layer chromatography in addition to other sugars as standards, in the solvent systems, npropanol-ethyl acetate-water (65:10:25), phenol-water (4:1) and n-hexane-ethyl ether-acetic acid (80:15:5), respectively. The plates were allowed to air-dry then sprayed with $50 \% \mathrm{H}_{2} \mathrm{SO}_{4}$ and heated at $110^{\circ} \mathrm{C}$ for $5 \mathrm{~min}$.

\section{Measurement of biosurfactant concentr- ation}

Biosurfactant concentration of the culture broth was estimated by determining the critical micelle concentration (CMC) which involves measuring the surface tension of serially diluted broth samples as described by Cooper et al. (1981). The CMC is defined as the concentration of surfactant necessary to initiate micelle formation. If more of the surfactant is present, there will be no further decrease in surface tension. The dilution factor obtained, which is the reciprocal of the $\mathrm{CMC}\left(\mathrm{CMC}^{-1}\right)$, is proportional to the amount of surfactant present.

\section{Surface tension and critical micelle concentration}

Surface tension of the culture broth and purified biosurfactant was determined by the ring method (Kim et al., 2000) using Du-Nouy ring tensiometre (K6, Krüss, Hamburg, Germany) at room temperature $\left(30 \pm 2^{\circ} \mathrm{C}\right)$. The $\mathrm{CMC}$ of the purified biosurfactant was determined by measuring the surface tension of serially diluted known weight of the biosurfactant and plotting the surface tension as a function of the biosurfactant concentration (Gerson and Zajic, 1979). The critical micelle concentration value is defined as that point at which purified surface active compound no longer aggregates to form micelles.

\section{Assay of emulsification activity}

The emulsification activity of the biosurfactant was measured as described by Cooper and Goldenberg (1987). Briefly, 3.0 $\mathrm{ml}$ of different oil samples was added to 2.0 $\mathrm{ml}$ of the biosurfactant solution in a graduated test tube and vortexed at high speed for $2 \mathrm{~min}$. This was allowed to settle for 24 hours and the emulsification index $\left(E_{24}\right)$ was calculated by dividing the measured height of emulsion layer by the mixture's total height and multiplying by 100.

\section{Stability studies}

The effect of $\mathrm{pH}$ on surface activity was carried out by introducing the biosurfactant solution $(0.1 \%, \mathrm{w} / \mathrm{v})$ in $0.1 \mathrm{M}$-phosphate buffer, $\mathrm{pH}$ 7.0, into graduated test tubes and adjusting the $\mathrm{pH}$ to various values (2-12) by the addition of $\mathrm{HCl}$ or $\mathrm{NaOH}$ at room temperature (Zhang and Miller, 1992). The heat stability study was carried out by incubating the biosurfactant solution in $0.1 \mathrm{M}$ phosphate buffer, $\mathrm{pH} 7.0$ at different temperatures $\left(30-100^{\circ} \mathrm{C}\right)$ for $30 \mathrm{~min}$ and cooling to room temperature. The effect of salt concentration on biosurfactant activity was determined by adding different concentrations $(0-20 \%, \mathrm{w} / \mathrm{v})$ of $\mathrm{NaCl}$ to the biosurfactant solution and allowed to stand for $30 \mathrm{~min}$. The surface activity was determined in terms of surface tension and emulsification index. The emulsification index, measured using paraffin oil, and surface tension were respectively determined at the end of each treatment period.

\section{Acute toxicity test}


Acute toxicity studies were carried out following World Health Organization guidelines as adapted by Ashtaputra and Shah (1995). Ten mice (22-27 $\mathrm{g}$ each), five of each sex, were given $5.0 \mathrm{~g}$ biosurfactant in water $/ \mathrm{kg}$ body weight per os. Control mice were given only water in a similar manner. All the mice were weighed immediately before the administration of the biosurfactant solution or water and periodically after $4,10,16,23$ and 30 days, respectively. The mice were observed for any toxic symptoms during the experimental period after which they were sacrificed. The liver and kidney indices of sacrificed mice were determined at the end of the treatment period. The indices were determined as the ratio of weight of the liver or kidney to the weight of the animal.

\section{Soil column study}

A sandy loam soil obtained from the University of Nigeria, Nsukka demonstration farm was used in this study. The soil column study was performed by the method of Pruthi and Cameotra (1997). Glass columns $(40.0 \times 2.0 \mathrm{~cm})$, each packed with $80.0 \mathrm{~g}$ of the soil, were saturated with $25 \mathrm{ml}$ of engine oil and $22 \mathrm{ml}$ of kerosene, respectively. The efficiency of the biosurfactant solution in releasing the oil from the soil was tested by adding $100 \mathrm{ml}$ aqueous solution of $0.5 \%(\mathrm{w} / \mathrm{v})$ of the biosurfactant solution to the column. Distilled water only was used as control in flushing the soil column. Efficiency of oil recovery was estimated by measuring the volume of each, oil released.

\section{Statistical analysis}

All experimental set-ups and analyses were performed at least three times with at least three replicates of each test under each condition in all experiments. Means and standard errors were calculated for pooled results in all experiments for each test. Analysis of variance was performed on some of the data obtained to determine significant differences among the means.

\section{Results}

The surface-active glycolipid was isolated from the cell-free culture supernatant of Serratia marcescens NSK-1 cultivated in a sucrose-mineral salt medium. Figure 1 shows the production of the biosurfactant and growth characteristics of Serratia marcescens NSK-1 on minimal medium containing $2 \%(\mathrm{w} / \mathrm{v})$ sucrose at different time intervals. The surface tension, $\mathrm{pH}$ values and biosurfactant concentration recorded during growth of the organism are also shown in figure 1 . The results indicated that as cell growth and biosurfactant production continued, there was reduction in the surface tension and $\mathrm{pH}$ of the medium. Maximum cell count of $8.10 \times 10^{9} \mathrm{cfu} / \mathrm{ml}$ from an initial of $1.32 \times 10^{7} \mathrm{cfu} / \mathrm{ml}$ and minimum surface tension value of 36.8 dynes $/ \mathrm{cm}$ of the culture filtrate were achieved at $36 \mathrm{~h}$ at which maximum biosurfactant concentration of $2.7 \mathrm{gL}^{-1}$ was obtained.

Liquid-liquid partitioning in chloroform-methanol mixture and silica gel adsorption chromatography resulted in an enrichment of the active compound. The extract from the sucrose-grown cells was identified as glycolipid based on its positive chromogenic reactions with anthronesulphuric acid and $\alpha$-naphthol-sulphuric acid spray reagents after development in chloroform-methanol-acetic acid solvent. The isolated biosurfactant after purification was found to contain about $46.3 \%$ carbohydrate and $50.2 \%$ lipid. The thin- 


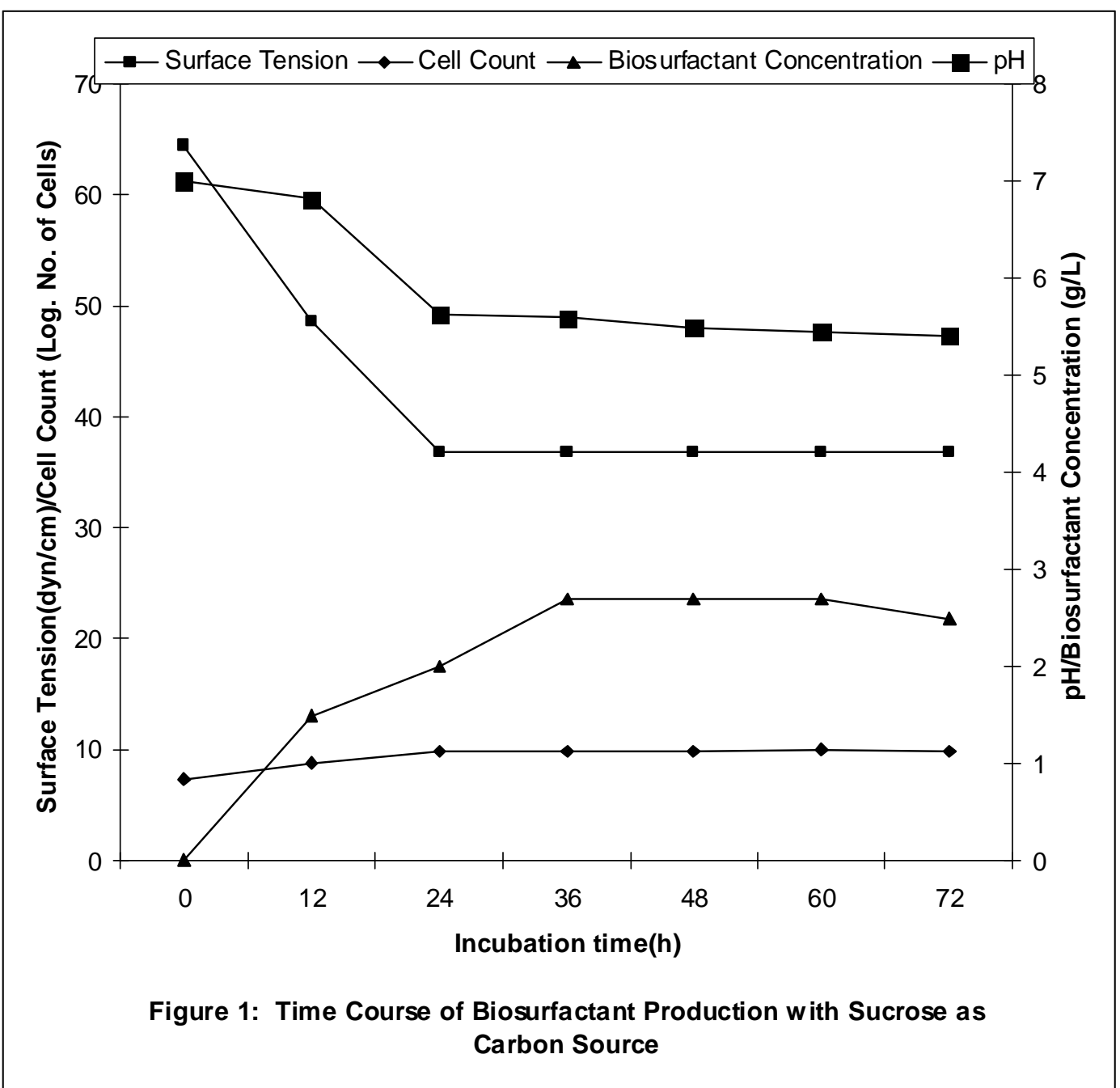

layer chromatogram of the glycolipid biosurfactant exhibited an $R_{f}$ value of 0.56 . The biosurfactant exhibited surface activity at low concentrations, reaching a critical micelle concentration of $52 \mathrm{mgL}^{-1}$.

The glycolipid was deacylated as described in the methodology section. The water soluble fraction from the saponified mixture was examined by thin layer chromatography. A single major spot was obtained, in phenol-water solvent, with $\mathrm{R}_{\mathrm{f}}$ of
0.59 and colour reaction very identical with those of standard sucrose. This revealed that the sugar moiety of the glycolipid was sucrose.

The biosurfactant obtained from Serratia marcescens NSK-1 was capable of forming stable emulsions with several oils tested. Emulsification activity of the biosurfactant was greater with vegetable oils than hydrocarbon oils (Tab. 1). Olive oil, a vegetable oil, showed the most stable 
emulsion with emulsification index of $100 \%$, while kerosene, hydrocarbon oil, exhibited the least stable emulsion after $24 \mathrm{~h}$ with emulsification index of $56 \%$.

Table 1. Emulsifying activity of biosurfactant with different oils.

\begin{tabular}{lc}
\hline Oil & Emulsification index (\%) \\
\hline Soybean & $98 \pm 0.8$ \\
Olive & $100 \pm 0.0$ \\
Palm & $80 \pm 2.2$ \\
Groundnut & $95 \pm 1.4$ \\
Engine & $78 \pm 2.2$ \\
Kerosene & $56 \pm 2.4$ \\
Paraffin & $90 \pm 1.6$ \\
Crude & $60 \pm 2.4$ \\
\hline
\end{tabular}

The effects of $\mathrm{pH}$, temperature and sodium chloride on the surface tension of the biosurfactant are shown in table 2 . The biosurfactant retained surface tension activity over wide $\mathrm{pH}$ and temperature ranges. The variations in surface tension values of the biosurfactant over the $\mathrm{pH}$ and temperature ranges were not significant $(\mathrm{p}<0.05)$. However, sodium chloride concentration of $16 \%(\mathrm{w} / \mathrm{v})$ and above significantly $(\mathrm{p}<0.05)$ inhibited the surface tension of the biosurfactant. In table 3 are shown the effects of $\mathrm{pH}$, temperature and sodium chloride concentrations on the emulsifying activity of the biosurfactant. The biosurfactant exhibited stable emulsion formation over wide ranges of $\mathrm{pH}$, temperature and sodium chloride concentration values. At $\mathrm{pH} 4$ and below and $\mathrm{pH} 12$, emulsification activity was significantly inhibited $(\mathrm{p}<0.05)$ but no significant effect was shown by temperature. Sodium chloride concentration of up to $12 \%(\mathrm{w} / \mathrm{v})$ showed no appreciable effect on biosurfactant activity. However, at sodium chloride concentration of $16 \%$ and above, emulsifying activity was significantly $(\mathrm{p}<0.05)$ inhibited.

Table 2. Effects of $\mathrm{pH}$, temperature and sodium chloride on surface tension of biosurfactant.

\begin{tabular}{lcc}
\hline Parameter & Value & $\begin{array}{c}\text { Surface tension } \\
\text { (dynes/cm) }\end{array}$ \\
\hline $\mathrm{pH}$ & 2 & $43.2 \pm 0.7$ \\
& 4 & $43.0 \pm 0.6$ \\
6 & $41.5 \pm 0.5$ \\
& 7 & $40.2 \pm 0.6$ \\
& 8 & $39.0 \pm 0.5$ \\
& 10 & $38.7 \pm 0.5$ \\
& 12 & $38.5 \pm 0.9$ \\
\hline Temperature $\left({ }^{\circ} \mathrm{C}\right)$ & 30 & $39.3 \pm 0.5$ \\
& 40 & $39.5 \pm 0.6$ \\
& 50 & $40.0 \pm 0.7$ \\
& 60 & $40.8 \pm 0.5$ \\
& 80 & $42.2 \pm 0.4$ \\
$\mathrm{NaCl}(\%, \mathrm{w} / \mathrm{w})$ & 100 & $43.1 \pm 0.6$ \\
\hline & 0 & $40.2 \pm 0.7$ \\
& 4 & $40.4 \pm 0.4$ \\
& 8 & $41.2 \pm 0.6$ \\
& 12 & $42.2 \pm 0.7$ \\
& 16 & $43.7 \pm 0.8$ \\
& 20 & $44.0 \pm 0.7$ \\
\hline
\end{tabular}

Table 3. Effects of pH, temperature and sodium chloride on emuls ifying activity of biosurfactant.

\begin{tabular}{lcc}
\hline Parameter & Value & $\begin{array}{l}\text { Surface tension } \\
\text { (dynes/cm) }\end{array}$ \\
\hline $\mathrm{pH}$ & 2 & $78.0 \pm 2.2$ \\
& 4 & $78.5 \pm 0.2$ \\
& 6 & $82.5 \pm 1.9$ \\
& 8 & $85.5 \pm 1.6$ \\
& 10 & $84.5 \pm 2.1$ \\
& 12 & $80.0 \pm 1.4$ \\
\hline Temperature & 30 & $85.5 \pm 1.2$ \\
$\left({ }^{\circ} \mathrm{C}\right)$ & 40 & $85.0 \pm 1.5$ \\
& 50 & $84.0 \pm 2.4$ \\
& 60 & $84.0 \pm 1.6$ \\
& 80 & $82.5 \pm 2.3$ \\
& 100 & $81.0 \pm 2.8$ \\
\hline $\mathrm{NaCl}(\%)$ & 0 & $85.0 \pm 0.8$ \\
& 4 & $82.0 \pm 1.4$ \\
& 8 & $80.5 \pm 2.5$ \\
& 12 & $78.0 \pm 2.4$ \\
& 16 & $73.0 \pm 2.2$ \\
& 20 & $67.5 \pm 2.5$ \\
\hline
\end{tabular}


Acute toxicity study of the biosurfactant on mice demonstrated that none of the mice given the biosurfactant per os died or showed any toxicity syndrome. The apparent increase in body weight of the test animals was not significant $(\mathrm{p}<0.05)$ and was comparable with that of control animals (Tab. 4a). There was also no significant difference $(\mathrm{p}<0.01)$ in the liver and kidney indices of the sacrificed experimental and control mice (Tab. 4b).

Table 4a. Effect of oral administration of biosurfactant on the growth of mice.

\begin{tabular}{lcc}
\multirow{2}{*}{ Days of growth } & \multicolumn{2}{c}{ Body weight $(\mathbf{g})^{*}$} \\
\cline { 2 - 3 } & Experimental & control \\
\hline 0 & $25.35 \pm 1.04$ & $25.28 \pm 1.57$ \\
4 & $25.98 \pm 0.65$ & $26.05 \pm 1.65$ \\
12 & $26.82 \pm 1.61$ & $26.70 \pm 1.53$ \\
20 & $27.84 \pm 1.75$ & $27.68 \pm 1.77$ \\
30 & $29.15 \pm 1.72$ & $28.75 \pm 1.83$ \\
\hline
\end{tabular}

*Values are means of body weight \pm standard deviation for 10 mice.

Table 4b. Organ indices of sacrificed mice fed with biosurfactant.

\begin{tabular}{lcc}
\hline \multirow{2}{*}{ Organ } & \multicolumn{2}{c}{ Organ index } \\
\cline { 2 - 3 } & Experimental & control \\
\hline Liver & 0.050 & 0.049 \\
Kidney & 0.007 & 0.007 \\
\hline Values are means of organ indices
\end{tabular}

The soil column study, which tested the effectiveness of the biosurfactant in possible microbial enhanced oil recovery, shows that $52 \%$ of engine oil and $62 \%$ of kerosene were recovered by the addition of the biosurfactant solution. Only $26 \%$ of engine oil and $30 \%$ of kerosene were recovered with distilled water.

\section{Discussion}

The Serratia marcescens NSK-1 strain isolated and used in this study produced glycolipid biosurfactant when grown in batch cultures with sucrose as the sole carbon and energy source. The production of biosurfactant and biomass during growth of Serratia marcescens NSK-1 in the sucrose medium was accompanied by decrease in surface tension of the fermentation broth. The decrease in surface tension indicates production of surfaceactive compounds by the bacterial strain. The results of the present study indicate that the biosurfactant production is growthassociated because a parallel relationship existed between growth and biosurfactant production as shown by surface tension reduction. The production of surface-active agent by $B$. cereus IAF-346 and biodispersan by Bacillus sp. strain IAF-343 (Cooper and Goldenberg, 1987) are examples of growth-associated biosurfactant production.

The majority of known biosurfactants are synthesized from water-immiscible hydrocarbons (Nitschke and Pastore, 2006). However, it was reported by Cooper et al. (1981), that the addition of a hydrocarbon to culture medium completely inhibited surfactant production by Bacillus subtilis. Meanwhile, the Serratia marcescens NSK-1 produced biosurfactant from water-soluble substrate, sucrose. According to Sandrin et al. (1990), glucose, fructose and sucrose were the best carbon substrates for the synthesis of biosurfactant by Bacillus subtilis. Moreover, it has been shown (Makkar and Cameotra, 1997) that watersoluble substrates are cheaper than hydrocarbons and are preferred because single-phase fermentation is simpler than biphasic fermentation.

Stability studies of the biosurfactant indicated it to be thermostable and also $\mathrm{pH}$ stable. The surfactant showed salt tolerance of up to $12 \%$. These findings suggest that 
the product obtained has potential application over a wide range of temperature and $\mathrm{pH}$ and relatively high salt environment. As such it could be very useful in situations where extreme conditions of temperature, alkaline $\mathrm{pH}$ and salinity are present such as enhanced oil recovery and bioremediation of soil and marine environments. Some biosurfactants have been found to be less stable over extreme $\mathrm{pH}$ range (Cirigliano and Carman, 1984; Zhang and Miller, 1992).

The ability of the Serratia marcescens NSK-1 biosurfactant to emulsify and stabilize the emulsion of a number of vegetable and hydrocarbon oils was examined. The oils did form emulsions with water in the absence of the biosurfactant; however, these emulsions rapidly separated in less than $10 \mathrm{~min}$. The addition of the biosurfactant to the emulsions stabilized them for over a $24 \mathrm{hr}$ period. The ability of biosurfactants to emulsify hydrocarbonwater mixtures has been demonstrated to increase hydrocarbon degradation significantly and is thus potentially useful in oil spill management (Abu-Ruwaida et al., 1991; Atlas and Bartha, 1992). The ability to form emulsions with vegetable oils and fats suggests potential application as cleaning and emulsifying agent in the food industry (Neto et al., 2008). A surfactant obtained from Rhodococcus strain AT-5 had lower emulsifying index towards shortchain hydrocarbons than for long-chain hydrocarbons (Abu-Ruwaida et al., 1991). The emulsifying activity of Serratia marcescens NSK-1 surfactant seemed not to be related to hydrocarbon chain length as it formed stable emulsions with oils of varying hydrocarbon chain lengths. The ability of the obtained biosurfactant to form stable emulsions with some hydrocarbons and different oils suggests considerable potential application in the petroleum industry as well as food and pharmaceutical industries.

The glycolipid biosurfactant was nontoxic to mice at the $5.0 \mathrm{~g} / \mathrm{kg}$ body weight dose tested, which was the highest dose recommended by the Food and Agricultural Organization/World Health Organization for a food additive. This is indicative of its nontoxic nature even when used as food additive or accidentally consumed. Moreover, the concentration of the surfactant, which could be consumed in whatever form, would be significantly less than the dose tested ( $5 \mathrm{~g} / \mathrm{kg}$ body weight). The low toxicity of biosurfactants has been recommended as a veritable advantage over synthetic surfactants (Desai and Banat, 1997; Kim et al., 2000).

The isolated biosurfactant, which removed $52 \%$ and $62 \%$ of engine oil and kerosene, respectively, is relatively effective in removing oil from a soil column saturated with known amounts of these hydrocarbons. However, Pruthi and Cameotra (1997) reported the recovery of $85-90 \%$ of the oil from a sand pack column when biosurfactant solution from Arthrobacter protophormie was used. The Serratia marcescens NSK-1 biosurfactant, therefore, has potential application in microbial enhanced oil recovery and bioremediation.

The results obtained in the present study showed the presence of indigenous bacteria in the tropical Nigerian soil capable of producing biosurfactant. The study also led us to suggest that the Serratia marcescens NSK-1 may have a significant application in the environmental, crude oil recovery and food industries. 


\section{C.U. Anyanwu, S.K.C. Obi and B.N. Okolo / Our Nature (2010) 8: 1-11}

\section{References}

Abu-Ruwaida, A.S., I.M. Banat, A. Salam and M. Kadiri 1991. Isolation of biosurfactant producing bacteria: product characterization and evaluation. Acta Biotechnol. 11:315-324.

Anyanwu, C.U., S.K.C Obi and B.N. Okolo 2008. Isolation of biosurfactant/bioemulsifierproducing bacteria from soil and sewage sludge. Global J. Pure Appl. Sci. 14(1): 103107.

AOAC (Association of Official Analytical Chemists) 1980. Official methods of analysis. The Association, Washington D.C.

Ashtaputer, A.A. and K. Shah 1995. Emulsifying property of a viscous exopolysaccharide from Sphingomonas paucimobilis. World $J$ Microbiol. Biotechnol. 11: 219-222.

Atlas, R.M. and R. Bartha 1992. Hydrocarbon biodegradation and oil spill bioremediation. Adv. Microb. Ecol. 12: 287-338.

Calvo, C., F.L. Toledo, C. Pozo, M.V. MartinezToledo and J. Gonzalez-Lopez 2004. Biotechnology of bioemulsifiers produced by microorganisms. J. Fd Agric. Environ. 2(3-4): 238-243.

Cameotra, S.S. and R.S. Makkar 2004. Recent applications of biosurfactants as biological and immunological molecules. Curr. Opinion Micrbiol. 7: 262-266.

Cirigliano, M.C. and G.M. Carman 1984. Isolation of bioemulsifier from Candida lipolytica. Appl. Env. Microbiol. 48: 747-750.

Cooper, D.G. and B.G. Goldenberg 1987. Surfaceactive agents from two Bacillus species. Appl. Env. Microbiol. 53: 224-229.

Cooper, D.G., C.R. MacDonald, S.J.B. Duff and N. Kosaric 1981. Enhanced production of surfactin from Bacillus subtilis by continuous product removal and metal cation addition. Appl. Env. Microbiol. 42: 408-412.

Dastgheib, S.M.M., M.A. Amoozegar, E. Elahi, S. Asad and I.M. Banat 2008. Bioemulsifier production by a halothermophilic Bacillus strain with potential applications in microbially enhanced oil recovery. Biotechnol. Lett. 30: 263-270.
Desai, J.D. and I.M. Banat 1997. Microbial production of biosurfactants and their commercial potential. Mcrobiol. Mol. Biol. Rev. 61: 41-64.

Dubois, M., K.A. Gilles, J.K. Hamilton, R.A. Rebens and F. Smith 1956. Colorimetric method for determination of sugars and related substances. Anal. Chem. 28: 350-356.

Georgiou, G., S.C. Lin and M.M. Sharma 1992. Surface-active compounds from microorganisms. Biotechnol. 10: 60-65.

Gerson, D.F. and J.E. Zajic 1979. Microbial biosurfactants. Process Biochem. 14: 20-29.

Hickey, A.M., M. Gordon, A.D.W. Dodson, C.T. Kelly and E.M. Doyle 2007. Effect of surfactants on fluoranthene degradation by Pseudomonas alcaligenes PA-10. Appl. Microbiol. Biotechnol. 74: 851-856.

Kim, S.H., E.J. Lim, S.O. Lee, J.D. Lee and T.H. Lee 2000. Purification and characterization of biosurfactants from Nocardia sp. L-417. Biotechnol. Appl. Biochem. 31: 249-253.

Kim, S.H., J.W. Jeon, B.H. Kim, C.Y. Ahn, H.M. Oh and B.D. Yoon 2006. Extracellular production of glycolipid biosurfactant, mannoslerythritol lipid by Candida sp. SY16 using fed-batch fermentation. Appl. Mirobiol. Biotechnol. 70: 391-396.

Lin, S.C. 1996. Biosurfactants: recent advances. J. Chem. Technol. Biotech. 66: 109-120.

Maier, R.M. and G. Soberon 2000. Pseudomonas aeruginosa rhamnolipids: Biosynthes is and potential applicants. Appl. Mic. Biotech. 54: 625-633.

Makkar, R.S. and S.S. Cameotra 1997. Utilization of molasses for biosurfactant production by two Bacillus strains at thermophilic conditions. $J$. Am. Oil Chem. Soc. 74: 887-889.

Mohan, P.K., G. Mukhla and E.K. Yanful 2006. Biokinetics of biodegradation of surfactants under aerobic, anoxic and anaerobic conditions. Water Res. 40: 533-540.

Mulligan, C.N. 2005. Environmental application for biosurfactants. Environ. Poll. 133: 183-198.

Neto, D.C., J.A. Meira, J.M. de Araujo, D.A. Mitchell and N. Krieger 2008. Optimization of the 
C.U. Anyanwu, S.K.C. Obi and B.N. Okolo / Our Nature (2010) 8: 1-11

production of rhamnolipids by Pseudomonas aeruginosa UFPEDA 614 in solid-state culture. Appl. Mic. Biotech. 81: 441-448.

Nitschke, M. and G.M. Pastore 2006. Production and properties of a surfactant obtained from Bacillus subtilis grown on cassava wastewater. Biores. Technol. 97: 336-341.

Pruthi, V. and S.S. Cameotra 1997. Production and properties of a biosurfactant synthesized by Arthrobacter protophormiae, an Antarctic strain. World J. Microbiol. Biotechnol. 13: 137-139.

Rosenberg, E. and E.Z. Ron 1999. High and low molecular mass microbial surfactants. Appl. Microbiol. Biotechnol. 52: 154-162.
Sandrin, C., F. Peypous and G. Michel 1990. Coproduction of surfactin and iturin A lipopeptides with surfactant and antifungal properties by Bacillus subtilis. Biotechnol. Appl. Biochem. 12: 370-375.

Suzuki, T., H. Tanaka and S. Itoh 1974. Sucrose lipids of Arthrobacter, Corynebacterium and Nocardia grown in sucrose. Agric. Boil. Chem. 38: 557-563.

Zhang, Y. and R.M. Miller 1992. Enhanced octane dispersion and biodegradation by a Pseudomonas rhamnolipid surfactant (biosurfactant). Appl. Environ. Microbiol. 58: 3276-3282. 